\title{
QUILOMBO, LUGAR DE FRONTEIRAS INTERCULTURAIS: DIÁLOGOS NO ENSINO DE HISTÓRIA
}

\section{QUILOMBO, A PLACE OF INTERCULTURAL BORDERS: DIALOGUES IN THE TEACHING OF HISTORY}

\author{
SILVA, Maria de Fátima Barbosa da ${ }^{1}$ \\ LIMA, Patrícia Ferreira de Souza ${ }^{2}$
}

\begin{abstract}
RESUMO
Intenciona-se apresentar resultados obtidos através de pesquisa, em nível de mestrado profissional no PPGEB, cujo problema era a elaboração de metodologias para a efetivação da lei 11.645-08, que reforça a obrigatoriedade da temática das matrizes culturais africanas e indígenas, em nossos currículos. Para elaborar estas metodologias, operamos com o conceito de interculturalidade de Néstor Canclini, que localiza nas cidades um lugar propício para os processos de hibridação, capaz de fomentar o encontro, mas também o respeito às identidades. Esta teoria foi colocada em ação no contexto histórico urbano de Niterói (RJ), como estudo de caso replicável, na E.M. Altivo César, através da metodologia de aulas oficina desenvolvida por Isabel Barca, a fim de se promover e constatar os processos educativos, pressuposto de uma Educação Intercultural, segundo Reinaldo Matias Fleuri. Para este artigo, selecionamos a oficina Quilombo (inter)cultural a fim de demonstrar alguns resultados obtidos nesta pesquisa acadêmica.
\end{abstract}

PaLAVRAs-ChaVe: Ensino de História; Interculturalidade; Lei 11.645/08; Currículo.

\section{AbSTRACT}

This article intends to present some results obtained through research, at the professional master's level, whose focus was the elaboration of methodologies for the implementation of law $11.645-08$, which reinforces the obligatory nature of African cultural themes, as well as indigenous ones, in our curricula. In order to elaborate these methodologies, we operate with the intercultural theory of Nestor Canclini, who sees in the context of the cities, a propitious place for the processes of hybridization, capable of fostering respect for identities. The theory was put into action in the urban context of Niterói (RJ), as a replicable case study, in the Municipal School Altivo César, through the methodology of workshops workshops developed by Isabel Barca, in order to promote / verify the educational contexts, Of Intercultural Education, according to Reinaldo Matias Fleuri. For this work, we selected the Quilombo (inter)cultural workshop in order to demonstrate some results obtained.

KeYWORDS: Teaching History; Interculturality; Law 11.645/08; Curriculum.

\footnotetext{
${ }^{1}$ Mestre em Ensino Básico pela Universidade do Estado do Rio de Janeiro (2016) e professora na rede municipal de Niterói. e-mail: silvamfbs@gmail.com.

${ }^{2}$ Doutora em História Social pela Universidade Federal do Rio de Janeiro (2006) e professora do ensino básico, técnico e tecnológico do Centro Federal de Educação Tecnológica Celso Suckow da Fonseca. e-mail: lima.patriciasouza@gmail.com
} 


\section{INTRODUÇÃo}

Em toda fronteira há arames rígidos e arames caídos. Néstor Garcia Canclini

O texto em epígrafe nos oferece instigantes reflexões no que tange aos distanciamentos que foram solidificando fronteiras entre grupos sociais, construídas simbolicamente, ao longo do tempo. Talvez seja preciso superá-las em prol de uma flexibilidade de contato ou trocas neste mundo globalizado, mantendo-se o respeito a cada expressão cultural em sua integridade. Uma perspectiva de front destes encontros culturais nos aproximaria desta cerca farpada na história dos portugueses, que conheceram os domínios indígenas e para cá trouxeram habitantes de África: uma questão a ser visitada no laboratório do ensino de História.

Este artigo intenciona expor alguns resultados obtidos através de pesquisa em nível de mestrado profissional ${ }^{3}$ a partir de uma reflexão teórico-prática acerca da aplicação da Lei no 11.645/08, a qual visa contribuir para a convivência respeitosa nas relações étnicas e culturais, através do reconhecimento e valorização das nossas identidades formadoras.

Optamos pelo termo "identidades" em sua forma plural, por considerar que 0 singular produz sentidos totalizantes. Exemplificando: no contexto do século XIX, a identidade nacional brasileira foi forjada como um artifício, no qual, entre as muitas intenções, estava o reforço da noção do Brasil como um país sem conflitos. Esta concepção idealizada foi garantida graças aos apagamentos efetuados, nos quais foram suprimidas outras facetas identitárias, como as culturais, as de classe e as de gênero, criando mecanismos de conformação e perda da valorização dos traços culturais e outras marcas formadoras dos vínculos entre esses grupos, de acordo com suas múltiplas pertenças.

A interculturalidade parece-nos uma perspectiva promissora em direção ao objetivo de superar as barreiras simbólicas, conforme propõe a citada Lei de 2008. Neste artigo procuramos apresentar alguns resultados obtidos com base na teoria intercultural desenvolvida pelo teórico argentino Néstor Garcia Canclini, a qual pode nos oferecer contribuições no sentido de trilhar caminhos para a superação desses limites, reconhecendo nas fronteiras, tanto os arames (des)tensionados quanto os ainda rígidos da questão social brasileira.

As abordagens propostas para a efetivação da Lei no 11.645/2008 empenham-se em focalizá-las com base nas realidades locais inseridas em tessituras amplas. A localidade de Niterói - RJ exemplifica estes espelhamentos, como estudo de caso, para a criação dos "contextos educativos relacionais", conforme o professor

\footnotetext{
${ }^{3}$ A pesquisa foi desenvolvida no Programa de Pós-Graduação em Ensino em Educação Básica (PPGEB)/UERJ e resultou também em um produto, cujo formato foi um livro que reuniu algumas oficinas para aplicação da Lei no 11.645/2008, intitulada: Histórias reveladas em águas escondidas: uma ponte intercultural entre as demandas sociais e o ensino de História.
} 
Reinaldo Fleuri (UFSC) e o entendimento da cidade, como um lugar propício às hibridações culturais ${ }^{4}$, como propõe Canclini.

A cidade, vista pelo olhar de Canclini, não é apenas um lugar de habitação, pois assume outros significados que são potencializados por meio das ações midiáticas produtoras de novos imaginários nas megacidades. As influências culturais transitam na velocidade dos meios de comunicação e as fronteiras das cidades assumem, no presente, configurações variadas, ao mesmo tempo em que persistem antigas estruturas. Uma dicotomia entre o que é moderno e o que é arcaico, dentro dos mesmos limites (CANCLINI, 2013, p. 213-218). Assim, é possível percebermos o fluxo destas interações em camadas. Uma arqueologia urbana que nos convida a ressentir os efeitos nem sempre harmônicos dos contatos entre grupos culturais distintos na trajetória histórica.

Considerando esta visão de Canclini, refletimos por meio da evolução urbana de Niterói, as potencialidades para explorarmos os fenômenos resultantes do contato de diversos referenciais culturais em um mesmo espaço nas suas múltiplas temporalidades: em Niterói ainda existem comunidades com peculiaridades socioculturais raras no contexto atual do Estado do Rio de Janeiro. Espaço de disputas em suas fronteiras simbólicas, acirradas em diversos momentos. Inicialmente, no contexto da colonização, em alianças entre conquistadores e nativos, com diversas experiências coloniais, a exemplo da construção da figura mítica de Araribóia ${ }^{5}$. A transferência da capital da Colônia, logo após a chegada da Corte Portuguesa em 1808, favorecendo sua ocupação e densificação. Além disto, espelha algumas relações de poder e potencialidades culturais em cidades que se constituíram por um algum tempo como capitais: Niterói, como capital do Estado do Rio de Janeiro e a cidade do Rio de Janeiro, capital do Império Ultramarino Português e depois do Brasil.

Aqui cabem as premissas de Canclini e Fleuri, que foram apresentadas aos estudantes da Escola Municipal Altivo César, por meio de situações-problemas, em aulas-oficinas com base no trabalho da historiadora portuguesa Isabel Barca, possibilitando a experimentação das metodologias elaboradas, as quais, entre outros resultados, contribuíram para despertar a alteridade, a atenção e atuação dos sujeitos envolvidos na pesquisa. O leitor poderá encontrar as três oficinas resultantes da pesquisa na dissertação: Histórias Reveladas em águas escondidas: uma ponte entre o Ensino de História e as demandas sociais e no livro: Diálogos Interculturais no ensino de História. Oficinas pedagógicas com aplicação da Lei 11.6450/08 (SILVA, 2016).

\footnotetext{
${ }^{4} O$ conceito hibridação, formulado por Canclini, provém de um empréstimo da biologia, no qual a cultura " $\mathrm{A}$ " ao interagir com a cultura " $\mathrm{B}$ " produz um novo artefato, portadora de elementos comuns, porém que não pertencem mais a nenhuma das duas anteriores.

${ }^{5}$ Araribóia era o líder da tribo dos temiminós e lutou ao lado dos portugueses contra os franceses. Anteriormente, a chegada dos europeus, já existiam rivalidades entre este grupo indígena e os tamoios, que se aliaram aos franceses. Como recompensa o rei de Portugal doou para Araribóia a terra de "São Lourenço dos Índios", atual Niterói (RJ) por isso ele é considerado o fundador da cidade. Em 2014, a Unidos da Viradouro exaltou este protagonismo.
} 
Dentre as três aulas-oficinas elaboradas e vivenciadas com o intuito de expor alguns procedimentos e resultados, destacamos a intitulada Quilombo (inter)cultural. Entre a imigração europeia, constante até nossos dias, em diferentes e diversas levas ao longo da História do Brasil e dos povos indígenas no Rio de Janeiro, sabe-se que os quilombos em constituição foram híbridos culturalmente, especialmente os mais vitalícios, formados por africanos, negros fugitivos do cativeiro ou libertos, mas também indígenas e brancos brasileiros de camadas pobres.

Antes de apresentar essa oficina, contudo, é importante compreendermos o impacto da Lei no 11.645/2008 sobre o currículo de História em suas articulações com os Direitos Humanos, especialmente se considerarmos que esses vêm sendo negados ao longo do percurso histórico às nossas minorias, e que a nossa ainda frágil democracia precisa ampliar o reconhecimento da legitimidade das reivindicações desses grupos. Como uma das consequências dessa ampliação, provocaríamos um fortalecimento para nossa soberania popular, frente aos constantes ataques, como àqueles que ocorrem na recente história do nosso país.

\section{A LeI No 11.645/ 2008 E O CURRÍculo de HISTÓRIA: REPRESENTAÇÃO E RECONHECIMENTO EM FAVOR DOS DiREITOS HUMANOS}

A Lei no 11.645 de 2008, é um instrumento jurídico direcionado ao ensino na educação básica para promover o respeito e o reconhecimento à nossa pluralidade cultural, como fruto das demandas sociais. Anteriormente a esta, fora publicada a Lei no 10.639/2003, igualmente alterando o texto da atual Lei de Diretrizes e Bases (LDB/1996) para favorecer o tratamento das relações identitárias no ensino.

É importante compreender a citada Lei publicada em 2008, no conjunto de outras normas, iniciando-se pela Constituição de 1988, a qual ficou conhecida como Constituição Cidadã, justamente por considerar os anseios da sociedade civil em relação a sua representatividade, participação política e exercício pleno de direitos e deveres, resultantes das mobilizações populares pelo retorno da democracia em nosso país, após o regime de exceção. Por seu intermédio, garantiram-se diversos direitos, cuja base são os princípios evidenciados no preâmbulo do texto constitucional, dentre os quais se destacam os princípios da pluralidade e respeito às diferenças, fundamentais ao exercício pleno da cidadania, reforçada, na CF-88, por meio de três importantes dimensões que sustentam os pilares para uma maior justiça social: o reconhecimento das identidades e dos direitos, a redistribuição material e simbólica, e a representação política (FRASER, 2007).

Embora as demandas a favor de uma sociedade justa encontrem materialidade nas leis mencionadas, é na prática cotidiana das escolas que poderemos encontrar um dos terrenos mais férteis, no qual se produzirão os efeitos duradouros para o nosso corpo jurídico e nossos anseios por equidade. Os discursos pelos Direitos Humanos correspondem a uma fonte de legitimidade nesse processo e vem desencadeando mudanças nos Currículos e no Ensino, e por isso também se apresentam como uma questão de relevância para este trabalho. 
DOI: $10.12957 /$ e-mosaicos.2017.28478

A Educação pautada nos Direitos Humanos considera a dignidade, a justiça, a igualdade e a liberdade, por meio do respeito à diversidade e à solidariedade, enfatizando a autonomia e protagonismo dos indivíduos, como essenciais para uma sociedade mais harmônica, ao mesmo tempo em que reconhece o valor de cada ser humano em sua individualidade. Para a promoção desse modelo de Educação, será necessário enfrentar o racismo, a discriminação e o preconceito.

Para Vera Candau (2013), é fundamental que se ampliem as conquistas, de modo a efetivar o fortalecimento das minorias através de três eixos: a formação do sujeito de direitos, já que na América Latina, estrategicamente, os distorcem como dádivas de políticos ou governos; favorecer o processo de empoderamento, "a potência que cada pessoa tem para que ela possa ser sujeito de sua vida e ator social" na coletividade e "os processos de transformação necessários para construção de sociedades verdadeiramente democráticas e humanas" (CANDAU, 2013, p. 4). É com vistas ao empoderamento que podemos correlacionar à promoção dos Direitos Humanos e a Lei no 11.645/2008, sendo esta um marco jurídico em direção à nossa cidadania.

No campo do currículo, buscaram-se caminhos para discussão das relações étnicas e culturais, bem como o necessário enfrentamento do preconceito para esta transformação, por meio da inclusão da temática "pluralidade cultural", aprovada como tema transversal nos Parâmetros Curriculares Nacionais (PCNs), um ano após a assinatura da atual LDB. Ainda que necessitem de maiores avanços, os PCNs expressaram um caráter inovador com propostas que sugeriram revisões no tocante ao ensino desde os fins da década de 1980:

É importante destacar que não se trata de mudar um foco etnocêntrico marcadamente de raiz europeia por um africano (ou indígena), mas de ampliar o foco dos currículos escolares para a diversidade cultural, racial, social e econômica brasileira (BRASIL, 2004, p. 26).

Ampliando-se o foco dos currículos para a diversidade, propõe-se o combate e a reparação dos danos históricos em favor do reconhecimento e valorização das expressões socioculturais e reivindicações destes povos de forma institucional. Representa uma mudança de paradigma que vem instigando a comunidade de historiadores, preocupada com outros modelos de ensino, aptos a interpretar as relações humanas sem condicioná-las à ideia de raça (QUIJANO, 2005; MUNANGA e GOMES, 2006). São necessárias, pois, novas formas de operar com a produção de saberes:

São operações intelectuais necessárias a um processo de ruptura epistemológica e cultural na educação brasileira. Esse processo poderá, portanto, ajudar-nos a descolonizar os nossos currículos não 
só na educação básica, mas também nos cursos superiores (ARAÚJO, 2012, p. 107).

Algumas destas operações intelectuais empreendidas ao longo desta pesquisa serão problematizadas no próximo tópico, para, em seguida, evidenciar os resultados mais significativos obtidos em experimentações em sala de aula, a fim de contribuirmos para esta ruptura cultural e epistemológica.

\section{IDENTIDADES: REFLEXÕES TEÓRICAS}

Com o objetivo de promover o reconhecimento das diferentes identidades culturais de modo a romper com uma lógica hierarquizante de saberes, na qual, subjacente, encontram-se desigualdades socioeconômicas produtoras de preconceitos, nos embasamos na perspectiva da interculturalidade e de como promover uma Educação Intercultural apta a dialogar com as diferenças, a fim de promover aprendizagens recíprocas. Para isso, cabe em primeiro lugar uma compreensão da palavra cultura e seus (re)significados no atual contexto cada vez mais globalizado.

Cultura, que vem do latim colere, ação, o cultivar algo, ato humano, não é um conceito fechado, sobretudo, em seu enfoque antropológico. Num primeiro momento nos cabe investigar a proposta de leitura da cultura que a vê como múltipla, como uma soma, em suas fronteiras mais ou menos definidas, com arames estendidos no tempo. Stuart Hall, sociólogo jamaicano e professor na Inglaterra, em diálogo com outros autores nos ajudou a estabelecer as pontes necessárias para essa compreensão. Em sua definição mais objetiva:

A cultura é uma produção. Tem sua matéria-prima, seus recursos, seu "trabalho produtivo". Depende de um conhecimento da tradição enquanto "o mesmo em mutação" e de um conjunto efetivo de genealogias. A cultura não é uma questão de ontologia, de ser, mas de se tornar (HALL, 2003, p. 43. grifos nossos).

Esta percepção implica na ruptura com noções fixas e acabadas. A cultura não é. Tornar-se-á. Construída nas práticas cotidianas, possibilita impulsionar nosso olhar para além das identidades culturais hegemônicas e assim resinificar os padrões predominantes, intervindo na nossa própria formação cultural. Ao ressaltarmos seu aspecto produtivo, contribuímos para que nos coloquemos em posição atuante. Se produzirmos cultura, podemos escolher se a queremos em perspectiva homogeneizadora ou se preferimos reconhecer o potencial criativo de outros povos e o incorporamos através dos processos de hibridação, isto é, na perspectiva da interculturalidade, pautados em outra concepção de Educação. 
Segundo Fleuri, pode-se compreender a Educação Intercultural como "uma proposta de "educação para a alteridade", aos direitos do outro, à igualdade de dignidade e de oportunidades, uma proposta democrática ampla (...) Trata-se, na realidade, de um novo ponto de vista baseado no respeito à diferença, que se concretiza no reconhecimento da paridade de direitos. É assim, um conceito utilizado para indicar "um conjunto de propostas de convivências entre diferentes culturas, buscando a integração entre elas sem anular sua diversidade, ao contrário, fomentando o potencial criativo e vital resultante das relações entre diferentes agentes e seus respectivos contextos" (FLEURI, 2005, p. 26)

A opção pela Educação Intercultural se justifica, na medida em que se propõe a estabelecer diálogos entre as diversas culturas, buscando pontos de contato, na perspectiva sintética de que: as culturas influenciam umas às outras, criam propostas de resistências e em decorrência destas interações, constroem novos artefatos culturais, sendo estes produtos e a possibilidade de intervenção.

Ao se enunciar a produção de saberes como um artefato criado pelas interações entre as culturas, isto é, em reciprocidade, a tendência natural seria seu reconhecimento como patrimônio coletivo e não, apenas, de uma determinada cultura. Esta perspectiva nos conduz para ao modo como se buscou a aplicação da Lei no 11.645/2008: evitando-se hierarquizações, e demonstrando que estas são vivas e como se relacionam entre si, ao proporcionar os contextos educativos relacionais (FLEURI, 2005).

A fim de contemplar/proporcionar tais contextos, buscamos colocar em ação a teoria intercultural desenvolvida pelo teórico Néstor Canclini. Este autor defendeu que é necessário promover-se políticas de hibridação mais democráticas, como meio de valorização das identidades. Considerando as imbricações entre identidades culturais e globalização, destacou o emblemático papel das cidades e, desta forma, nos ajudou a compor práticas com base em sua densa teoria, pautadas na perspectiva de valorização das identidades para se combater as relações desiguais tendo como foco os lócus privilegiados dos sujeitos que ali estejam inseridos, tal como nas relações estudadas na cidade de Niterói, campo empírico deste trabalho:

Destaco as fronteiras entre países e as grandes cidades como contextos que condicionam os formatos, os estilos e as contradições específicos da hibridação (...) Poucas culturas podem ser descritas como unidades estáveis, com limites precisos baseados na ocupação de um território delimitado (CANCLINI, 2013, p. 29-30).

Para sua pesquisa, Canclini elegeu a cidade do México, sustentando que:

Dentro da cidade, são seus contextos familiares, de bairro e de trabalho, os que controlam a homogeneidade do consumo, os desvios nos gostos e nos gastos. Numa escala mais ampla, 'o que' se entende 
como cultura nacional continua servindo de contexto para seleção do exógeno (...) Contudo, estas comunidades de pertencimento e controle estão se reestruturando. A que conjunto a participação numa sociedade construída predominantemente pelos processos globalizados de consumo nos faz pertencer? (CANCLINI, 1996, p.61).

Para este autor, o fundamental é o foco nos processos de hibridação e não apenas seus resultados:

(...) a ênfase na hibridação não enclausura apenas a pretensão de estabelecer identidades "puras" ou "autênticas". Além disso, põe em evidência o risco de delimitar identidades locais autocontidas ou que tentem afirmar-se como radicalmente opostas a sociedade nacional ou à globalização (...) Como consequência, é absolutizado um modo de entender a identidade (...) (CANCLINI, 2013, p. 19 a 23).

Esta teoria foi aplicada na Escola Municipal Altivo César, situada no município de Niterói (RJ), para apropriação dos estudantes, por meio de experimentações ligadas à Educação Intercultural. Assim, no próximo tópico, serão apresentadas algumas atividades práticas realizadas com os estudantes que participaram de aulasoficinas, em que se verificou a eficácia teórica da Educação Intercultural no cotidiano escolar e como os estudantes estavam se apropriando dos princípios interculturais, tendo por base alguns referenciais conceituais desenvolvidos por Canclini aqui sintetizados.

\section{A TEORIA EM AÇÃO: QUILOMBO (INTER)CULTURAL}

Apresentaremos alguns resultados obtidos a partir das reflexões teóricas, apoiadas na metodologia das aulas-oficinas de Isabel Barca (2004). A conjugação dos termos "aulas" e "oficinas" indicam um processo de aprendizagem em que os saberes compartilhados são colocados em prática. O lugar comum para o vocábulo oficina é aquele em que o aprendiz é capaz de conhecer e empregar com proficiência algum ofício por meio da observação e da experimentação. É também um espaço que funciona como laboratório, no qual artefatos são testados e aprimorados, gerando apropriações ao elaborar produtos finais.

Nessas aulas, o aluno é convidado a refletir sobre situações problema, como pressuposto para a ampliação da sua orientação temporal, com base na premissa de que a problematização das nossas questões no presente, nos leva a inquirir o passado. Em uma aula oficina de História, as fontes documentais recebem especial destaque: o documento histórico passa a ser utilizado de modo que o aluno se sinta motivado a apropriar-se desse instrumento e fazer as conexões entre o passado e a sua realidade criticamente. 
Procuramos evidenciar para os estudantes as formas de atuação dos grupos identitários, muitas vezes invisíveis nos processos culturais hegemônicos, a fim de contemplar narrativas plurais em hibridações com outros grupos, por meio das alteridades as quais, como desafio, intenciona reparar, em ação, alguns efeitos colonizatórios. Propôs-se, então, em atividade de campo, que os estudantes ficassem atentos aos embates contra a permanência do Quilombo no Grotão, e como este vem reagindo.

O Quilombo do Grotão integra um conjunto das chamadas comunidades tradicionais, situadas no Parque da Serra da Tiririca (região localizada nos limites de Niterói e Maricá- RJ), (Figura 1), no bairro do Engenho do Mato, em Niterói-RJ, e se expande até os limites de Maricá-RJ. Isto significa que apesar de ser uma comunidade rural, insere-se no contexto urbano. Uma característica peculiar do ponto de vista da teoria de Canclini, que nos ajuda a pensar as dicotomias entre o rural e o urbano, o moderno e o tradicional, entre outros dilemas, indicando alguns itinerários em resposta a como reagir diante dos encontros em relações desiguais, ao longo do percurso histórico (QUILOMBO, 2013).

Fig.1: Infográfico: comunidades tradicionais na reserva do parque da Serra da Tiririca - Niterói, RJ.

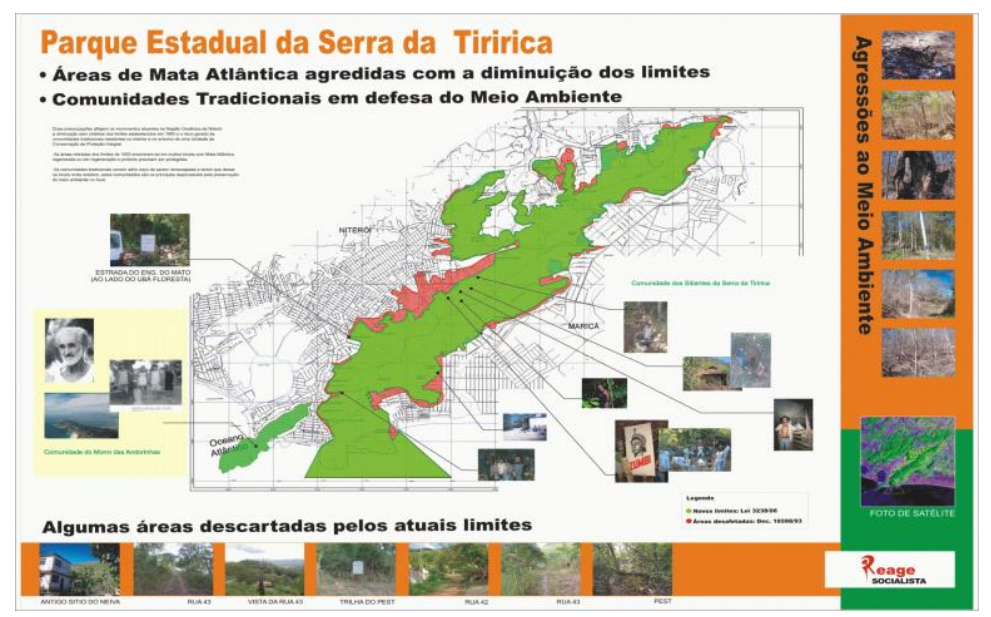

Fonte: http://mandatorenatinhopsol.blogspot.com.br/2012/08/ampliacao -do-parque-estadual-da-serra.html. Acesso em: 11 de agosto de 2017.

Os problemas locais envolvendo essas comunidades resultam do processo de apagamento de suas práticas socioculturais em oposição aos valores capitalistas modernos, e, em decorrência, produtoras das invisibilidades. Chocam-se interesses imobiliários e industriais, desde a construção de condomínios à produção pesqueira em larga escala, colocando em risco o modo de viver dessas comunidades.

Para seu auto fortalecimento e dos outros grupos, o Quilombo do Grotão tem assumido posição de vanguarda e liderança na conservação das memórias, na representação política e em frentes alternativas, como os encontros em que ocorrem a roda de samba e o uso de painéis solares para captação de energia. Ressalte-se 
que esse é um papel histórico que vem sendo desempenhado nesses campos de resistências, os quais, desde os seus primórdios, buscavam acolher as demandas de outros grupos, indígenas, mestiços e até brancos, entre outros, em conflitos semelhantes, remontando ao período colonial.

A conceituação de Quilombo foi problematizada, em sala de aula, no intuito de desconstruir as imagens canônicas que colaboram para a visão equivocada do "negro" como vítima que não resistiu e, em geral, viveu sob tortura e trabalhos aviltantes. Com base no infográfico (Fig. 1) e no conceito de quilombo resinificado a fim de superarmos uma visão descritiva que remonta a definição do Conselho Ultramarino, que o percebia no

tempo histórico passado, cristalizando sua existência no período em que vigorou a escravidão no Brasil, além de caracterizarem-no exclusivamente como expressão da negação do sistema escravista, aparecendo como espaços de resistência e de isolamento da população negra (SCHMITT; TURATTI, 2002, p. 2).

Contudo, uma produção científica menos restritiva e com um olhar mais afinado com as realidades sociais e dinâmicas

subsidiou a luta política em torno das reivindicações da população rural negra, que sofrendo expropriações incessantes, se colocava como um segmento específico no palco dos movimentos sociais. Desta forma a denominação quilombo se impôs no contexto da elaboração da Constituição de 1988 (SCHMITT; TURATTI, 2002, p. 2).

Este amparo teórico, com aceitação na Magna Carta, vem contribuindo para reverter alguns efeitos provocados pela escravidão, mas ainda precisamos avançar, especialmente se considerarmos o fato de que as revisões reducionistas sobre o conceito em questão produzem invisibilidades estratégicas, silenciadoras de conflitos, retirando a responsabilidade de políticas públicas no tocante a (re)distribuição de terras. Para romper com esta invisibilidade acolhida na historiografia oficial, buscamos uma conceituação capaz de contemplar as "complexas redes sociais permeadas por aspectos multifacetados que envolveram, em determinadas regiões do Brasil, inúmeros movimentos sociais e práticas econômicas com interesses diversos". Como propôs Flávio dos Santos Gomes (2015), por meio do conceito "campo negro". Foi justamente a partir desta conceituação que compreendemos o Quilombo do Grotão.

Assim, iniciamos o nosso trabalho com os estudantes, nessa oficina, com a conceituação de Quilombo, melhor compreendida por meio de atividade prática, na 
qual os educandos puderam entrevistar uma liderança quilombola. Segundo Renatão do Quilombo, que foi representante eleito no legislativo municipal de Niterói (RJ) e considerável liderança política local, a formação do Quilombo do Grotão teve seu marco na inadimplência com os trabalhadores.

Na verdade, a nossa luta... meu vô lutou, meu pai lutou e eu agora estou dando continuidade a essa luta que a gente tem aqui na serra da Tiririca. No princípio meu avô veio pra cá pra trabalhar pra fazenda na década de 1920. Trabalhou 28 anos como colono. Quando a fazenda faliu, eles deram esse pedaço de terra pra meu avô e pra mais uns vinte e cinco colonos. Mas só a parte alta, na época não tinha valor (era um morro) (RENATÃO DO QUILOMBO, entrevista aos alunos do Altivo César, 2016).

Os estudantes, por meio da atividade de campo ao Quilombo do Grotão, compreenderam o importante papel que este desempenha: como catalisador das resistências, ao transformar suas expressões culturais, no diálogo intercultural com as demais comunidades, em estratégias de lutas, encaminhando espaços para hibridações. A conceituação de hibridações já havia sido anteriormente apresentada e compreendida pelos estudantes por meio de outras atividades de campo e em outras oficinas. O contato com os sujeitos do Quilombo que enunciaram respostas criativas para suas demandas constituiu mais um reforço para ampliar esta compreensão em outras dinâmicas sociais.

Começamos pela compreensão, na atividade de campo, do Quilombo como algo vívido e não estanque no tempo, constatada por meio de um projeto ali desenvolvido, de implantação do painel solar. Este projeto foi a solução para o obstáculo da energia elétrica, diante da limitação para criar novas redes elétricas. Em diálogo com outros setores, chegou-se ao uso de painéis solares como lícita e ecológica solução, inclusive mais de acordo com os valores daquela comunidade.

Para adquiri-los, a comunidade do Grotão aproveitou a venda de consumação na tradicional roda de samba, que todos os meses acontece no Quilombo, e por meio de uma campanha de doação, através de um site especializado. Demonstrações de que o quilombo se propõe atuante e nada estagnado, como o querem as suas tradicionais definições, e que exemplificam a estratégia traçada por Canclini como opção para o dilema da defesa da(s) identidade(s) ou globalizar-se:

Não penso que, hoje, a opção central seja entre defender a identidade ou nos globalizar. Mais do que contrapor identidades essencializadas à globalização, trata-se de indagar se é possível instituir sujeitos em estruturas sociais ampliadas (CANCLINI, 2010, p.28). 


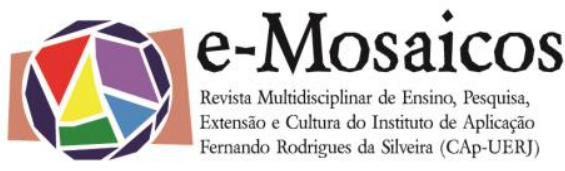

DOI: $10.12957 /$ e-mosaicos.2017.28478

Essa é uma indagação que o Quilombo do Grotão vem buscando responder por meio de suas ações, inserindo-se cada vez mais em estruturas sociais ampliadas: percebendo a necessidade de fortalecimento das comunidades tradicionais do Parque da Serra da Tiririca, foi criada a ACOTEM - Associação da Comunidade Tradicional do Engenho do Mato, integrando-as formalmente. As reuniões da ACOTEM, inicialmente visavam os objetivos políticos comuns àqueles grupos, mas passaram a ganhar espaços outros, formando intensa rede de conhecimento e de atuação no sentido de contracultura que se fortalece em números de adeptos e ganha voz social, por intermédio das suas ações interculturais. Lugar fronteiriço de cultura, não fechado, em arames que se curvam, em busca sempre de outros interlocutores:

A gente recebe gente do exterior, a gente tem um combinado com uma agência que todo mundo que vem de fora, paga uma muda de mata atlântica e daí no dia do meio ambiente, a gente faz o plantio junto com as crianças. E pode vir as crianças para participar. Em junho cada escola vai trazer uma maquete para semana do meio ambiente. E quero convidar vocês. Aqui acontece também roda de capoeira e roda de cura com um pajé. É muito bonito (RENATÃO DO QUILOMBO, entrevista aos alunos do Altivo César, 2016).

As atividades pedagógicas que são desenvolvidas no Quilombo do Grotão e divulgadas, durante a atividade prática, para os estudantes da Escola Municipal Altivo César são demonstrativas dos valores compartilhados pelos membros daquela comunidade, sempre em busca de outros interlocutores, como caminho para fortalecimento nas lutas em face de outros interesses que não se coadunam com uma sociedade democrática, na qual os espaços de convivências são respeitados.

Entre os obstáculos que o Quilombo do Grotão e as demais comunidades assistidas pela ACOTEM precisam enfrentar, o principal diz respeito à própria permanência no local. A área foi tombada como patrimônio universal da humanidade pela UNESCO, o que implica em algumas restrições para a garantia da preservação ambiental. Apesar disso, é uma zona de litígio com fortes pressões imobiliárias.

Nessa atividade prática, os estudantes puderam ouvir alguns relatos sobre as arbitrariedades e violências sofridas por àquelas comunidades, especialmente motivadas por tensões geradas pela especulação imobiliária. Os estudantes também acessaram documentos que faziam parte do acervo do quilombo e que foram disponibilizados durante a aula de campo: o termo de doação das terras que antes era a fazenda "Boca do Mato", motivada pela inadimplência com os salários, reportagens sobre as consequências da especulação imobiliária e sobre a reforma agrária, com ênfase na situação dos quilombolas.

Diante desses relatos vivenciados pelos quilombolas, os estudantes expressaram muitas inquietudes: por que a comunidade local não participava nas mobilizações em defesa daquele patrimônio natural e cultural? Por que esse 
distanciamento, se afinal era tema de tanta relevância, inclusive para a economia local? Questionavam também por que a mídia não cumpria sua função social em auxílio a esses problemas? Relatavam que nada sabiam a respeito, porque não era televisionado, contudo, reconheciam as imbricações das mobilizações para suas vidas.

A ausência de exposição desses problemas nas mídias convencionais dificulta essa tomada de conhecimento por parte de outros segmentos da sociedade e impede alianças recíprocas. O Quilombo do Grotão, no entanto, não é inerte a esta falta de comunicação e aproveita todo o seu potencial, utilizando espaços físicos e simbólicos para preservação e divulgação de sua memória e revigora sua mobilização política pelo viés da cultura: o terreno onde acontecem as reuniões da ACOTEM, bem como as rodas de samba, foi transformado em museu com artefatos, símbolos e imagens dos personagens que ajudam a compreender os entrelaçamentos das culturas na busca pela afirmação política.

Durante a atividade de campo, os estudantes puderam fluir dessas históricas marcadas em cada espaço do quilombo. Sobre a origem das rodas de samba no Quilombo do Grotão, o Renatão expressou, através de sua entrevista aos estudantes durante a aula prática, a importância das alianças em benefício dos interesses em comum e como estas trocas vem se ampliando. Nessas rodas de samba, também é possível saborear a feijoada do Grotão:

Essa feijoada surgiu (...) este espaço era menor (onde acontecem a roda de samba e a feijoada), a gente se reunia, ai no final a gente fazia alguma coisa pra comer e assim surgiu a feijoada daqui, mas era só pra gente era uma brincadeira, mas aí começou a juntar gente e as pessoas começaram a cobrar e agora vem gente de tudo que é lugar (RENATÃO DO QUILOMBO, entrevista aos alunos do Altivo César, 2016)

Os membros do Quilombo do Grotão preparam uma surpresa para os estudantes: o almoço foi justamente esta tradicional iguaria da cultura brasileira, momento em que podemos dialogar um pouco mais sobre a natureza híbrida da feijoada e suas adaptações: prato milenar que mistura vários tipos de carnes, legumes e verduras de origem mediterrânea, com o feijão e a farinha de origem indígena. Embora muitos acreditem que a feijoada era o alimento dos escravos, por se tratar de uma mistura de diversos gêneros de alimentos, o que facilitaria 0 emprego de sobras da mesa dos seus senhores, há aqueles que defendem que a feijoada era cardápio dos ricos (PINTO, 2017). De qualquer forma, esta ilustração serviu não apenas ao paladar como ao intelecto daqueles jovens que saíram com uma sensação do quanto ainda havia por se descobrir a cerca de toda essa realidade que mobilizamos em nossa cultura. 
Além disso, esta experiência de campo foi um incentivo ao protagonismo dos estudantes: espelhando a mobilização do Quilombo do Grotão os educandos propuseram exposições na escola, encenações teatrais, jornais murais para divulgação, em reconhecimento às demandas do Quilombo do Grotão e dos problemas vividos em comum, como a questão da preservação ambiental. Estes resultados revelam que conquistas culturais são recíprocas e que é possível trilhar caminhos para reação, em estratégicas aprendizagens, tal como a que nos auxiliou na finalização das oficinas, consumando a proposta de criar contextos relacionais para a interculturalidade, na qual os estudantes pudessem aprofundar a sua própria alteridade, pelos vínculos em comum das problemáticas étnica e culturais aqui elencadas e com isso capacitá-los ainda mais enquanto sujeitos ativos.

\section{CONSIDERAÇÕES FinaIS}

O desafio para a efetivação da Lei no $11.645 / 2008$, reforçada pela discussão sobre a temática indígena após a Lei no 10.639/2003 ter assegurado a temática afrobrasileira no espaço privilegiado da sala de aula, é um imperativo com o qual, profissionais da Educação, nos comprometemos a fim de promover a transformação de muitas práticas enraizadas no âmbito social: o racismo, o preconceito e a discriminação que se naturalizam, cotidianamente, e produzem efeitos prejudiciais para a nossa sociedade, e, no campo pedagógico, o que nos exige, além de conhecimento, sensibilidade para intervir no próprio contexto.

Esta pesquisa representou um empenho para atender às demandas sociais propostas pelo campo jurídico. A efetiva aplicação destas prescrições jurídicas tende a contribuir para equalizar estas situações, na medida em que colabora para o reconhecimento e valorização das identidades africanas e indígenas, evidenciando expressões socioculturais, mobilizações sociopolíticas e enunciando a voz de seus sujeitos, o que corresponde a um direito pautado na perspectiva dos princípios universais dos Direitos Humanos.

A partir da experiência do quilombo intercultural foi possível perceber não somente os produtos das hibridações, mas também os processos históricos que remontam aos problemas compartilhados por indígenas e africanos, cativos à época da escravidão, e, face a seus efeitos, continuam estabelecendo diálogos tendo este espaço e a cultura como importantes catalisadores das mobilizações políticas e das resistências. Assim, o aluno, ao se apropriar destes argumentos, poderá perceber que a cultura em trocas com outros sujeitos é um importante mecanismo para o fortalecimento de sua participação política e de vínculos comunitários.

\section{REFERÊnCIAS BIBLIOGRÁfICAS}

ARAÚJO, Cinthia Monteiro de. Por outras histórias possíveis: em busca de diálogos interculturais em livros didáticos de histórias. Tese (Doutorado em Educação). Rio de Janeiro: PUC, 2012. 
DOI: $10.12957 /$ e-mosaicos.2017.28478

BRASIL. Secretaria de Educação Fundamental. Parâmetros curriculares nacionais. pluralidade cultural, orientação sexual. Brasília: MEC/SEF, 1997.

. Lei no 10.639/2003. Disponível em: http://www010.dataprev.gov.br/sislex/ paginas/42/2003/10639.htm. Acesso em: 8 de maio de 2015.

. Lei no 11.645/2008. Disponível em: http://www.planalto.gov.br/ccivil_03/ _ato2007-2010/2008/lei/l11645.htm. Acesso em: 8 de maio de 2015.

- Diretrizes Curriculares Nacionais para a Educação das Relações ÉtnicoRaciais. Brasília: MEC/SEF, 2004.

CANCLINI, Néstor Garcia. Consumidores e cidadãos: conflitos multiculturais da globalização. Rio de Janeiro: UFRJ, 1996.

. Culturas híbridas: estratégias para entrar e sair da modernidade. São Paulo: Edusp, 2013

CANDAU, Vera. Educação e Direitos Humanos, currículo e estratégias pedagógicas. Disponível em: http://www.dhnet.org.br/dados/cursos/edh/redh/04/4_6_vera_ candau_edh.pdf. Acesso em: 8 de agosto de 2015.

FLEURI, Reinaldo Matias. Educação Intercultural: desafios e perspectivas da identidade e pluralidade étnica no Brasil. PQ/CNPQ. Florianópolis, 2000.

GOMES, F. S. Mocambos e quilombos - uma história do campesinato negro no Brasil. São Paulo: Companhia das Letras, 2015.

HALL, Stuart. A identidade cultural na pós-modernidade. Rio de Janeiro: DP\&A, 2006.

PINTO, Tales dos Santos. História da feijoada. In: Brasil Escola. Disponível em: <http://brasilescola.uol.com.br/historia/historia-feijoada.htm>. Acesso em: 12 ago. 2017.

QUILOMBO, RENATÃO. Entrevista concedida aos estudantes da Escola Municipal Altivo César. IN: SILVA, Maria de Fátima B. Diálogos Interculturais no ensino de História. Oficinas pedagógicas com aplicação da Lei 11.645-08. Dissertação (Mestrado Profissional em Ensino da Educação Básica). Rio de Janeiro: UERJ, 2016.

SILVA, Eduardo P. Nunes. Azul Celeste em Vermelho: o projeto carnavalesco de Martinho e Ruça na Unidos da Vila Isabel entre 1988 e 1990. Dissertação (Mestrado em História). Rio de Janeiro: UERJ, 2014.

SILVA, Maria de Fátima B. Diálogos Interculturais no ensino de História. Oficinas pedagógicas com aplicação da Lei 11.645-08. Dissertação (Mestrado Profissional em Ensino da Educação Básica). Rio de Janeiro: UERJ, 2016. 
DOI: $10.12957 /$ e-mosaicos.2017.28478

SCHMITT, Alessandra. TURATTI, Maria C. M. CARVALHO, Maria C. P. de. $A$ atualização do conceito de quilombo: identidade e território nas definições teóricas. Ambiente \& Sociedade - Ano V - No 10 - $1^{\circ}$ Semestre de 2002. Disponível em: http://www.scielo.br/pdf/asoc/n10/16889.pdf. Acesso em: 6 de agosto de 2015. 